\title{
Control of $\mathrm{NO}_{\mathrm{x}}$ from A DI Diesel Engine With Hot EGR And Ethanol Fumigation: An Experimental Investigation
}

\author{
GURUMOORTHY S HEBBAR ${ }^{1}$, ANANTHA KRISHNA BHAT ${ }^{2}$ \\ ${ }^{1}$ Corresponding Author, Mechanical Engineering Department, Christ University Faculty of Engineering \\ Kumbalagodu-Kengeri, Bangaluru 560074, Karnataka State, INDIA, \\ ${ }^{2}$ Co Author,Mechanical Engineering Department, Gogte Institute of Technology Udyambhag, Belguam-590008,
} Karnataka State, INDIA.

\begin{abstract}
Oxides of nitrogen (NOx) are one of the major hazardous pollutants from diesel engine emission. Various control technologies exist for its control but each technique has advantages and disadvantages. At present, there is no single optimal technique that can control NOx without other side effects. Technologies available for NOx reductions either cause fuel penalty or increase other polluting emissions. Exhaust Gas Recirculation is an effective technique in controlling oxides of nitrogen in diesel engines but do not become attractive at higher loads and higher percentage of recirculated gas as combustion tends to deteriorate at higher loads leading to reduced engine thermal efficiency and increased hydrocarbon and smoke emission. Ethanol is an established alternate fuel used in diesel engine either as a blend or fumigated using a separate injector. Experiments were conducted on a single cylinder diesel engine to examine the effect of EGR temperature on NOx and other emission constituents. Hot EGR gave better results up to $30 \%$ EGR rate but EGR cooling was found better in terms of NOx reductions and efficiency. It was found that NOx reductions up to 88\% was possible but at the cost of about 18\% loss in thermal efficiency. This inconvenience of fuel penalty caused by Exhaust Gas Recirculation can be overcome by applying ethanol fumigation. The findings of experimental results for this combined technique are presented in this paper. With this combined technique, apart from reducing the oxides of nitrogen, engine power and efficiency approaches to that of only diesel combustion condition with improvements in smoke, hydrocarbon and carbon monoxide emissions.
\end{abstract}

Key Words:- EGR; Ethanol; Fumigation; NOx; Smoke; HC; Efficiency

\section{Introduction}

Diesel engines are used in a wide variety of applications including transportation of men and materials, construction equipments, power generation and many farming process because of their reliability, durability, and power and fuel efficiency. However, diesel engines have also been recognized by its polluting emissions affecting the air quality. Health assessments have listed diesel emission constituents as a probable human carcinogen; contribute to chronic respiratory problems such as asthma. Oxides of Nitrogen (NOx) from the diesel combustion are highly dangerous. They form nitric acids and related salts reacting with moisture and in the presence of sun light they form volatile organic compounds (VOC) leads to the formation of ground level ozone finally reaching the earth surface along with rain or as fog, dews or dry particles. Such acids, salts deteriorates the health of human, vegetation, water dependant creatures apart from damaging metal parts, building and monuments. Ground level ozone ( $\mathrm{smog}$ ) can irritate eyes and cause loss of visibility during daytime and also damages vegetation and reduces crop yields [1-3]

\section{Exhaust Gas Recirculation for reducing oxides of Nitrogen}

In recent years Exhaust gas recirculation (EGR) has been popular to reduce NOx emissions in light duty diesel engines. EGR involves routing a fraction of engine exhaust gas into the intake manifold where it mixes with the incoming fresh air before being taken in to cylinder [4-6]. Peak combustion temperatures are one of the main factors for the formation of NOx and it can be greatly suppressed when the $\mathrm{O}_{2}$ concentration in the combustion chamber is reduced. On using EGR, some of the $\mathrm{O}_{2}$ in the cylinder contents is replaced by exhaust gas constituents like $\mathrm{CO}_{2}$, and $\mathrm{H}_{2} \mathrm{O}$. With the local $\mathrm{O}_{2}$ concentration reduced, injected diesel has to spread wider to form a combustible mixture and as a consequence of this, two factors become very prominent. Firstly, as given amount of fuel will have to diffuse over a wider region to find sufficient $\mathrm{O}_{2}$, some of EGR constituents like $\mathrm{CO}_{2}$ and water vapor are also included in the mixture [6-8]. These high specific heat EGR contents absorb heat energy released by combustion [9-10]. The second factor is due to reduced availability of oxygen. Ignition delay increases as availability of oxygen reduces [11] extending the combustion to expansion stroke causing early quenching of the flume and thus reducing total combustion duration. The net effect of both factors is to reduce the peak combustion temperature thereby reducing the chances of NOx formation. EGR cooling before it is mixed with fresh intake air also affects the emission and performance parameters [12]. 


\section{Alcohol as diesel engine fuel}

In the past much attention was not focused for alcohol as CI engine fuel [13-14]. In the recent past alcohols have proved that they are established substitutes for the petroleum based fuels during dual fuel operation. Alcohol alone as motor fuel has not become reality yet owing to some of the practical difficulties. They are

1. More volume of alcohol fuel than diesel fuel for the same mass [13]

2. Alcohol does not mix with diesel completely while trying to blend and tend to separate in the presence of any trace of water $[15,16]$

3. Very low cetane number of alcohol against desired high value. Ignition delay increases with lower catane number [17]

4. Alcohols are poor lubricators as compared to diesel fuels $[13,16]$

5. Poor auto-ignition quality of alcohol fuel show rapid burning and tend to knock where as high latent heat of vaporization results in to combustion quenching $[13,16]$

Literature indicates injection of ethanol in a CI engines results in to increase in thermal efficiency, torque; decreased $\mathrm{HC}$ and smoke [18]. Both ethanol blending and fumigation give similar results but fumigation technique is reported to be more convenient and effective also the optimum percentage for ethanol fumigation was reported as $20 \%$ [19]

\subsection{Ethanol fumigation}

Ethanol (Ethyl Alcohol- $\mathrm{C}_{2} \mathrm{H}_{5} \mathrm{OH}$ ) fumigation involves injecting ethanol in to the air stream of the engine. The injected alcohol vapourises and is compressed along with the air in the cylinder. Diesel fuel is injected in the normal manner but a portion of the power from the engine is provided by the alcohol typically 1 $30 \%$ [20]. The expected benefits of ethanol are higher efficiency, higher specific power and lower emissions. Higher latent heat of vaporization gives higher charge density [21-27]; and higher laminar flame speed makes them to be operated with higher air fuel ratio [25] when used with diesel fuel. In addition, heat release rates are low for alcohols resulting in lower NOx emissions and combustion noise [22]. High temperature of EGR is supposed to help ethanol vapourise and mix with air during compression stroke. Alcohol in combination with EGR is expected to show better results in terms of both performance parameters and engine out emissions. The results are discussed in the following sections.

\section{Test Engine}

The test engine is a Kirloskar AV1 engine facilitated with data acquisition systems (DAS) for recording engine data measurements. External EGR is routed into the intake manifold through a one inch diameter GI pipe. The EGR line emerges right after the exhaust port and enters the midpoint in the intake manifold. This ensures that the EGR is well mixed with the fresh charge. An orifice meter is used to determine the flow rate of EGR. Percentage of exhaust gas is taken as ratio of amount of exhaust gas recirculated to total engine exhaust gas (volume basis). AVL smoke meter is used to measure the smoke level and INDUS ${ }^{\circledR} 5$ gas analyzer for $\mathrm{O}_{2}$, $\mathrm{CO}, \mathrm{CO}_{2}, \mathrm{HC}$ and $\mathrm{NOx}$ measurements. Details of the test engine are mentioned in table 1. The ethanol fumigation is achieved through an additional injector attached just before the inlet manifold and in the line of EGR route inclined and in opposite direction to EGR flow. The injection pump is driven by the cam shaft of the engine. Cam is so designed to inject the ethanol in 5, 10, 15 and 20\% of total amount of diesel injected in a cycle for a given load. This arrangement is shown the fig.1.

Table 1. Test Engine Specifications

\begin{tabular}{|l|l|}
\hline Type & 4-Stroke, Single Cylinder Diesel Engine \\
\hline Make & Kirloskar AV -1. \\
\hline Loading & Electrical, Resistive Air Heaters \\
\hline Rated Power & $3.7 \mathrm{KW}, 1500 \mathrm{RPM}$ \\
\hline Bore \& Stroke & $85 \mathrm{~mm} \times 110 \mathrm{~mm}$ \\
\hline Cylinder Capacity & $624.19 \mathrm{cc}$ \\
\hline Compression Ratio & $16.5: 1$ \\
\hline Pressure Transducer & Piezo Sensor, Range: 2000 PSI. \\
\hline Starting & Auto Start. \\
\hline
\end{tabular}




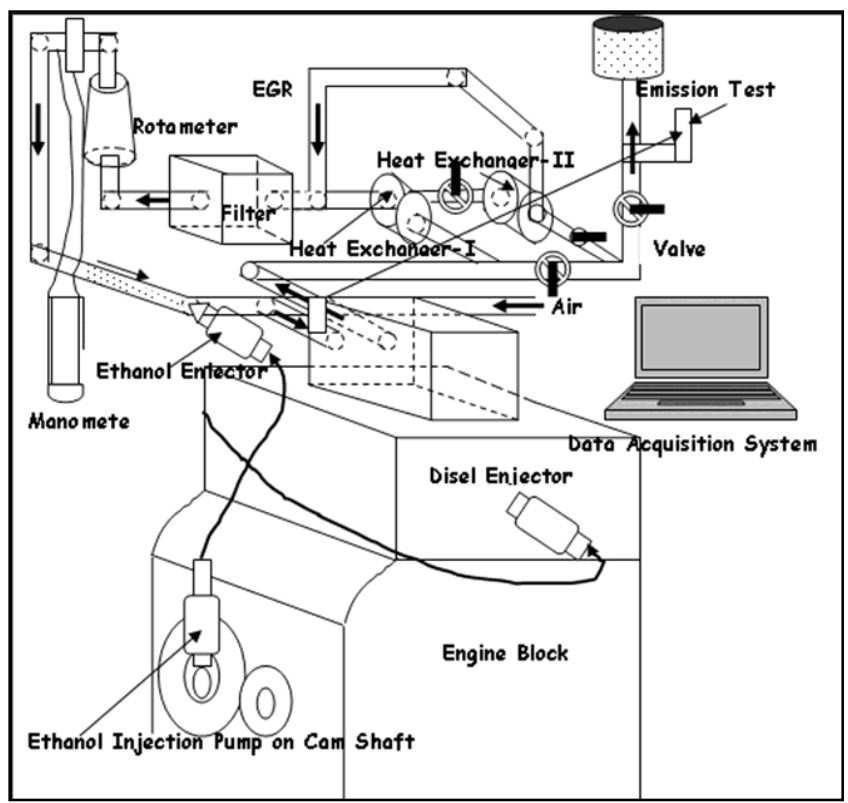

Fig.1. Layout of experimental set up

\section{Results and Discussions}

\subsection{Effect of ethanol fumigation on exhaust gas temperature}

When EGR is applied without cooling, the exhaust gas temperature decreases due to dilution and thermal effects $(6,7,10,28)$. Ethanol injection was employed with hot EGR as it helps quick vapourisation of alcohol and subsequent mixing (29). High latent heat of vapourisation has a cooling effect as ethanol vapourise.

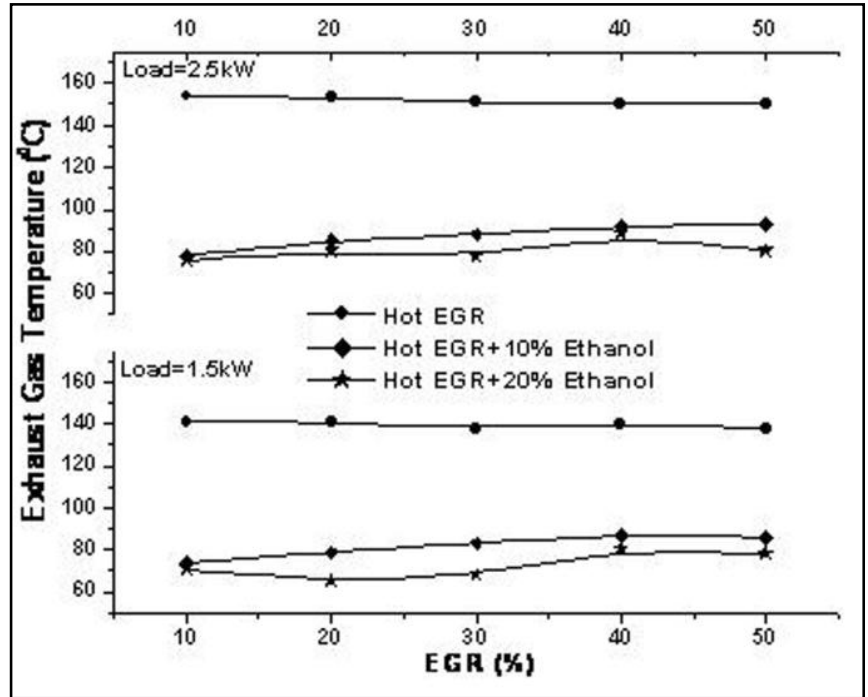

Fig.2. Effect of EGR \% on exhaust Gas Temperature for different percentage of ethanol fumigation

Reductions in the exhaust gas temperature, which is an indicative of combustion temperature, further reduce when alcohol is injected at the intake. These results are presented in the fig2. For all dose of ethanol injections exhaust gas temperature are lower as compared to combustion with hot EGR. These aspect favorers reduced NOx formation.

\subsection{Effect of ethanol fumigation on emission of Carbon Dioxide}

Ethanol in comparison to diesel fuel contains some oxygen atoms and thus $\mathrm{CO}_{2}$ percentage is found to increase as EGR percentage increase. An increase in $\mathrm{CO}_{2}$ with increase in EGR rate was recorded when EGR was applied without ethanol injection. $\mathrm{CO}_{2}$ emissions do not change appreciably when ethanol was fumigated in combinations with EGR. These results are plotted for two loads in fig 3. 


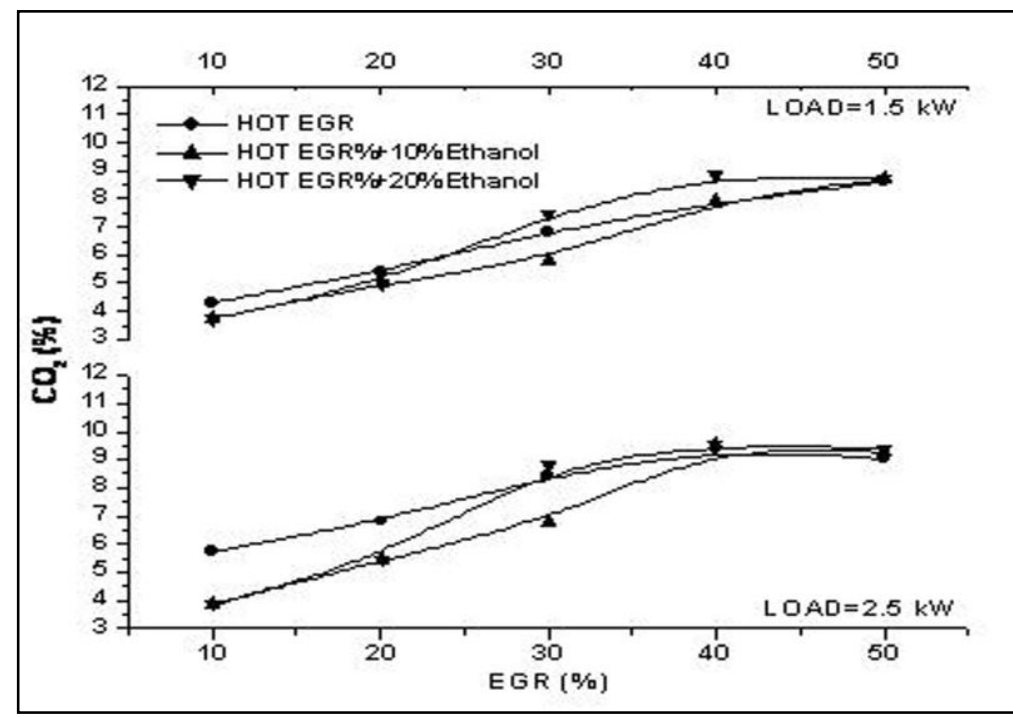

Fig. 3. Emission of Carbon dioxide for different percentage of ethanol fumigation and EGR

\subsection{Effect of ethanol fumigation on emission of hydro carbons}

Emission of $\mathrm{HC}$ in the engine tail pipe is mainly a result of incomplete combustion. Presence of burnt gas (EGR) causes reduced availability of oxygen due to thermal throttling [30-31]. Ethanol fumigation during intake is expected to supply oxygen as ethanol in comparison to diesel fuel contains some oxygen atoms. Ethanol molecules contain 35 percent oxygen, and serve as an "oxygenate" to raise the oxygen content. But HC emission tend to reduce with ethanol fumigation only up to $10 \%$ injection and thereafter for $15 \%$ and $20 \%$ ethanol dose HC concentration increase even more than the values corresponding to only hot EGR mode (fig 4). With higher percentage of ethanol more cooling effects are expected resulting into lower rates of HC oxidations and also at higher dose of ethanol leads to formation of quenching layers

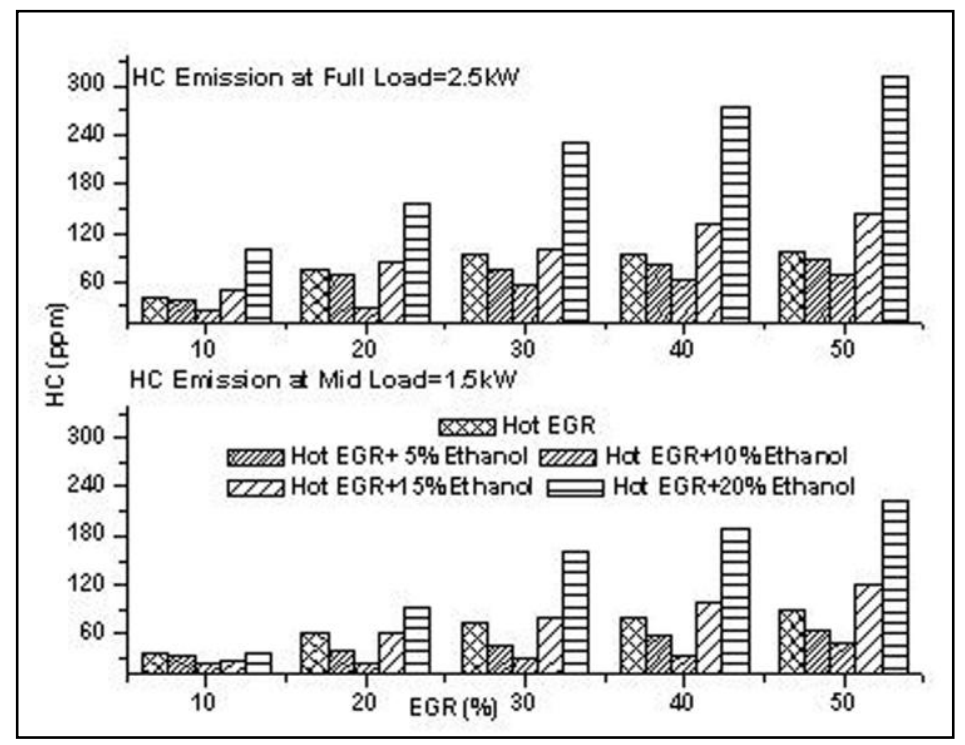

Fig. 4. Emissions of Hydrocarbons for different percentage of ethanol fumigation and EGR

\subsection{Effect of ethanol fumigation on smoke emission}

Smoke is an outcome of thermal cracking of the large hydrocarbon fuel molecules and the carbon agglomerates into particles (soot) visible as smoke in the exhaust. It is a result of condensation of hydrocarbon. Presence of soot is mostly through incomplete combustion of fuel, condensation of hydrocarbons due to decreased combustion temperatures with small contributions from the lubricating oil [32]. More difficult pulverisation of the heavy fuel droplets and non-homogeneous mixing leads to incomplete combustion resulting into emission of smoke and HC. Availability of oxygen and combustion temperature are critical in soot 
oxidation and hence reduced smoke emission. Presence of ethanol favors oxidation process and smoke level is expected to reduce and literatures suggest that ethanol is best fuel to minimize smoke and particulate matters.

In Fig5, smoke value in percentage are plotted for two load conditions for hot EGR and EGR with different percentage of ethanol fumigations. Results indicate hot EGR emit more smoke as compared to EGR with ethanol fumigation. As fumigation quantity is increased from $5 \%$ to $15 \%$ the smoke level tend to decrease remarkably. But further increase in fumigation of ethanol records slightly higher values mainly due to reduced temperatures where soot oxidation is hampered.

In fig 6 the smoke levels for different cases are compared with only diesel (no EGR and ethanol) case. Smoke levels are found nearly same or even less for ethanol fumigation with EGR when compared to only diesel case (taken as reference). 5 to $15 \%$ of ethanol injection generates less smoke at all EGR rates. Smoke levels are very low up to mid load $(1.5 \mathrm{~kW})$ with 5 to $15 \%$ of ethanol injection along with hot EGR. Increased smoke levels with higher percentage of EGR can be overcome with 5 to $10 \%$ ethanol injection. This result is obvious as HC concentrations (Fig.4) show similar trend

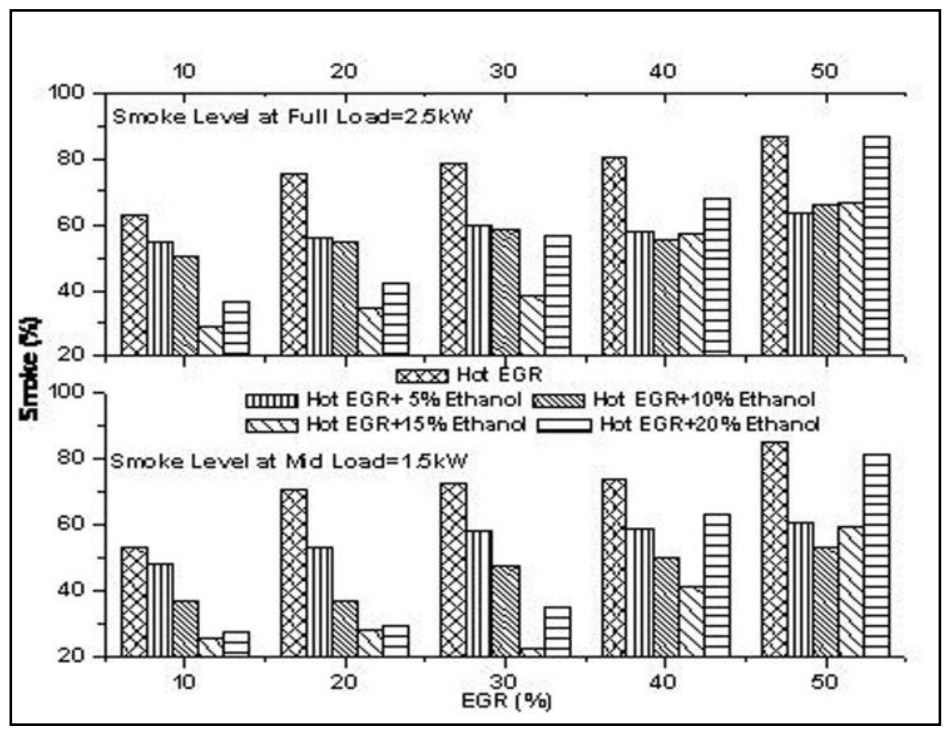

Fig. 5. Smoke Emissions for different percentage of ethanol fumigation and EGR

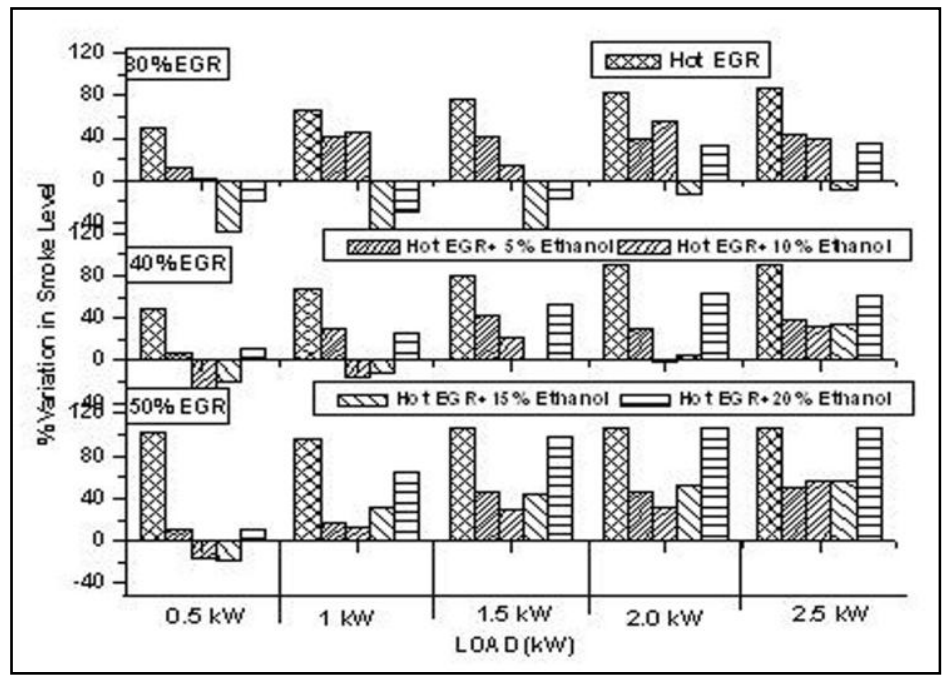

Fig. 6. Percentage variations in smoke emission for different percentage of ethanol fumigation and EGR with reference to only diesel values

\subsection{Effect of ethanol fumigation on Oxides of Nitrogen (NOx) emission}

Diesel NOx emissions result from the thermal fixation of atmospheric nitrogen and its oxidation in the presence of high combustion temperature. Control of these emissions can be achieved by reducing the peak flame temperatures. EGR reduces the peak temperature by diluting the charge with burnt exhaust gas. Higher 
NOx emission reductions can be achieved through higher percentage of EGR but results into a loss in thermal efficiency and increased HC and smoke emission especially at higher EGR values and higher loads. Alcohols generally give lower fuel heat release rates, resulting in lower NOx emissions. With fumigation of ethanol in the presence of EGR enables admit more percentage EGR with greater reductions in NOx along with comparatively lower emissions of HC and smoke. Fig.7 shows the reductions of NOx for part load and full load with and without ethanol fumigation. In fig. 8 percentage reductions in NOx concentration at all loads for $50 \%$ EGR are compared for different cases. It can be observed that NOx concentration remains 10 to $15 \% \%$ lower for ethanol fumigation case as compared to without fumigation for entire range of load.

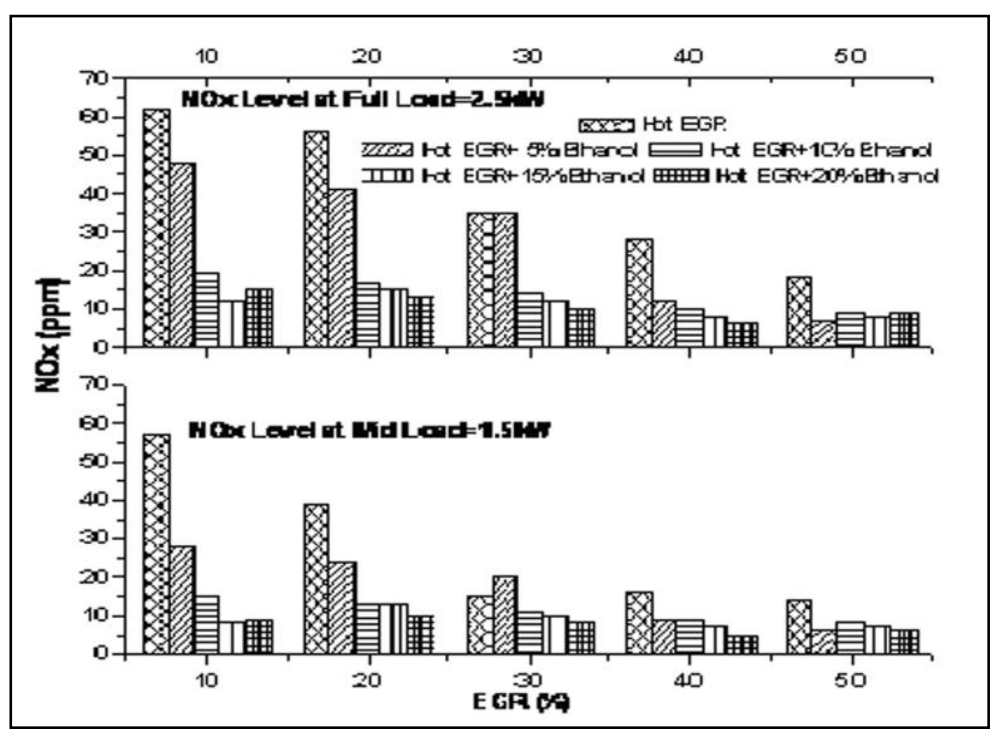

Fig. 7 Percentage variations in smoke emission for different percentage of ethanol fumigation and EGR with reference to only diesel values

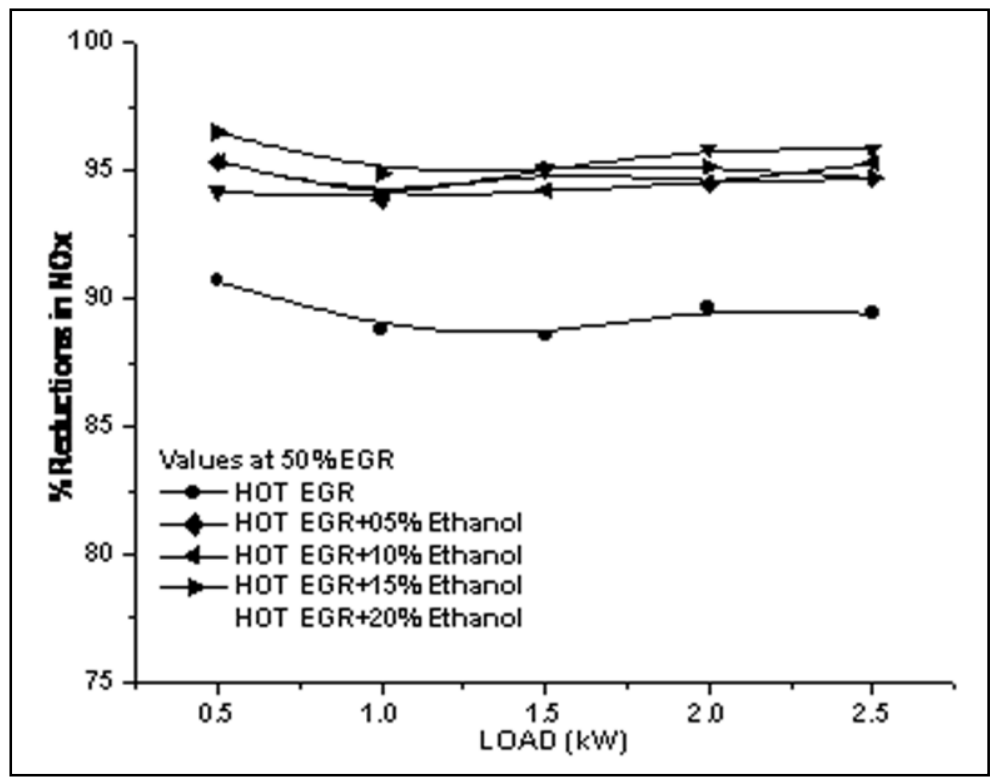

Fig. 8 Percentage variations in smoke emission for different percentage of ethanol fumigation and EGR with reference to only diesel values

\subsection{Effect of ethanol fumigation on engine torque}

In fig 9, torque values are compared for hot EGR and fumigation cases with reference to only diesel case. When only EGR was applied loss in the torque occurred due to compression of hot expanding gases during compression and incomplete combustion due to diluted mixture. Additional injection of ethanol adds energy and nearly compensates for this loss. 10 to $15 \%$ ethanol injection results in to improved torque especially at higher EGR rates. 


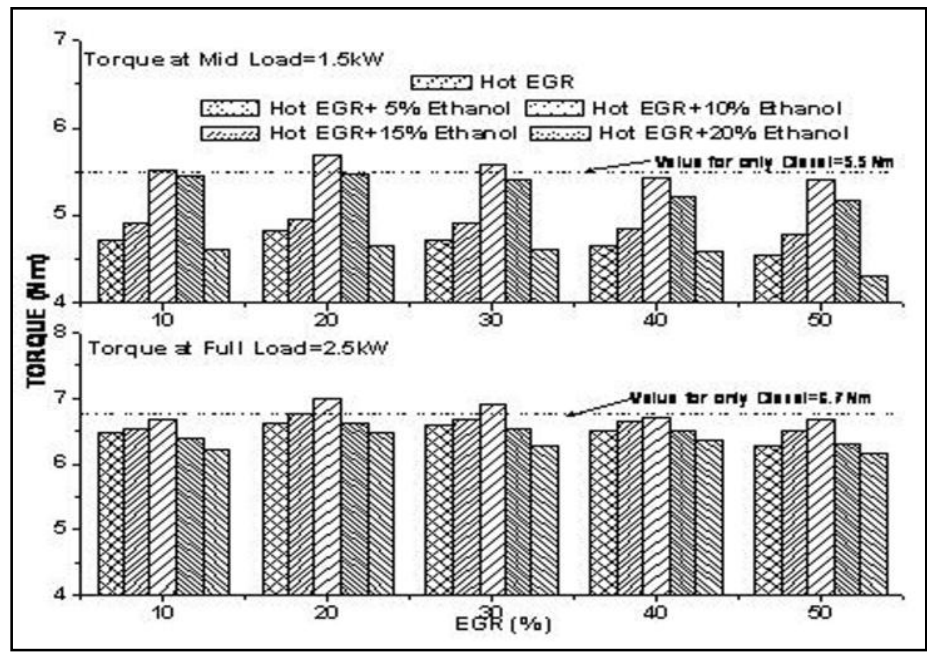

Fig. 9 Engine torque for different EGR percentage for two load conditions

\subsection{Effect of ethanol fumigation on thermal efficiency}

Thermal efficiency is a measure of engine output power and fuel consumption. For an engine operating at constant speed, the torque increase as the load on the engine increase. Ethanol fumigation improves the efficiency when compared to corresponding values of hot EGR for all loads. The thermal efficiency values are comparatively better for 5\% and 10\% ethanol fumigation as compared to higher dose (fig.10). Fig (11) depicts the results of thermal efficiency for part load $(1.5 \mathrm{~kW})$ and full load $(2.5 \mathrm{~kW})$ for 10 to $50 \%$ EGR. The variation in thermal efficiency is negligible up to $30 \%$ EGR and tends to slightly decrease thereafter particularly for only hot EGR case. This is mainly attributed to incomplete combustion as the percentage of EGR increases which consequently reduces the torque and hence the engine output power. Ethanol fumigation along with hot EGR shows improved efficiency in this region.

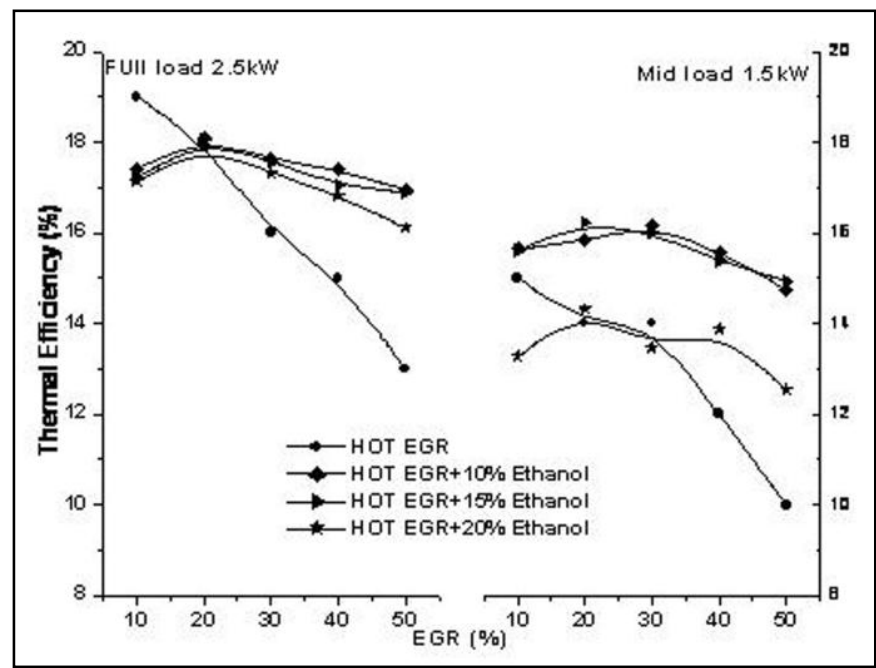

\section{Fig. 10 Thermal efficiency for different EGR percentage for different ethanol fumigation percentage for} two load conditions

The fig(12) show the comparison of variation in thermal efficiency in percentage for three different cases; (i) Hot EGR. (ii) Hot EGR with different percentage of ethanol fumigation and (iii) only diesel, which is taken as reference. It is clear that thermal efficiency reduces for both cases of hot EGR with and without fumigation when compared with only diesel case. However for ethanol fumigation with EGR, these percentage losses are less and values are more close to reference values. The loss in efficiency is limited to around $20 \%$ for fumigation where as it is up to $40 \%$ for without fumigation case at maximum of 50\% EGR. Another observation is that loss of efficiency is very marginal (around 5\%) for up to $10 \%$ ethanol fumigation and 30\% EGR and then it slightly increase (around 20\%) as the fumigation percentage increases. 


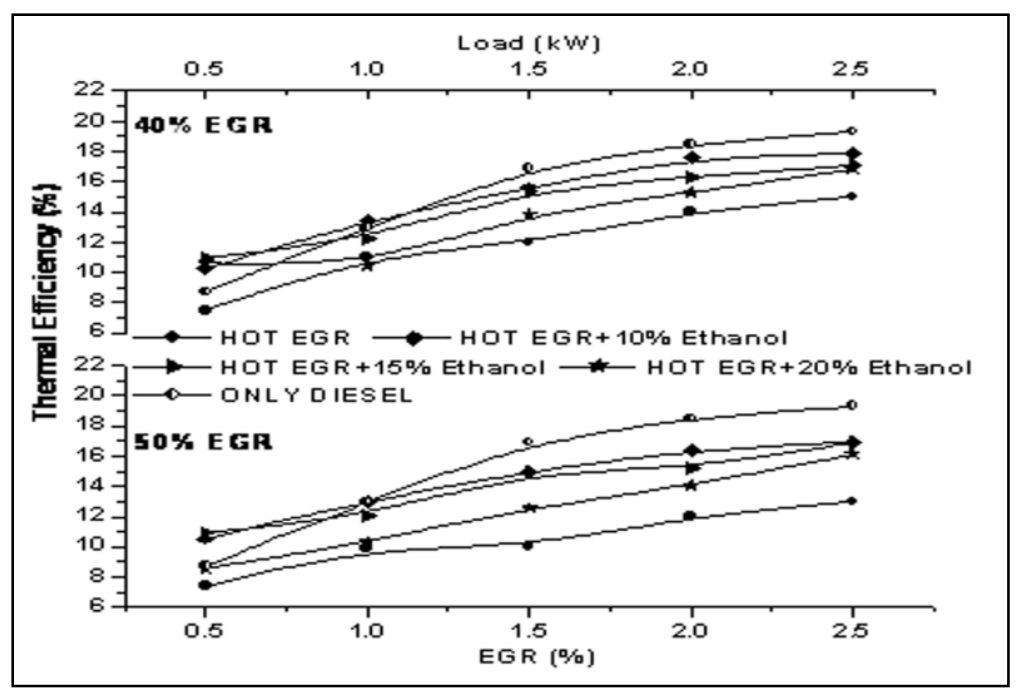

Fig. 11 Thermal efficiency for different EGR percentage for different ethanol fumigation percentage for two load conditions

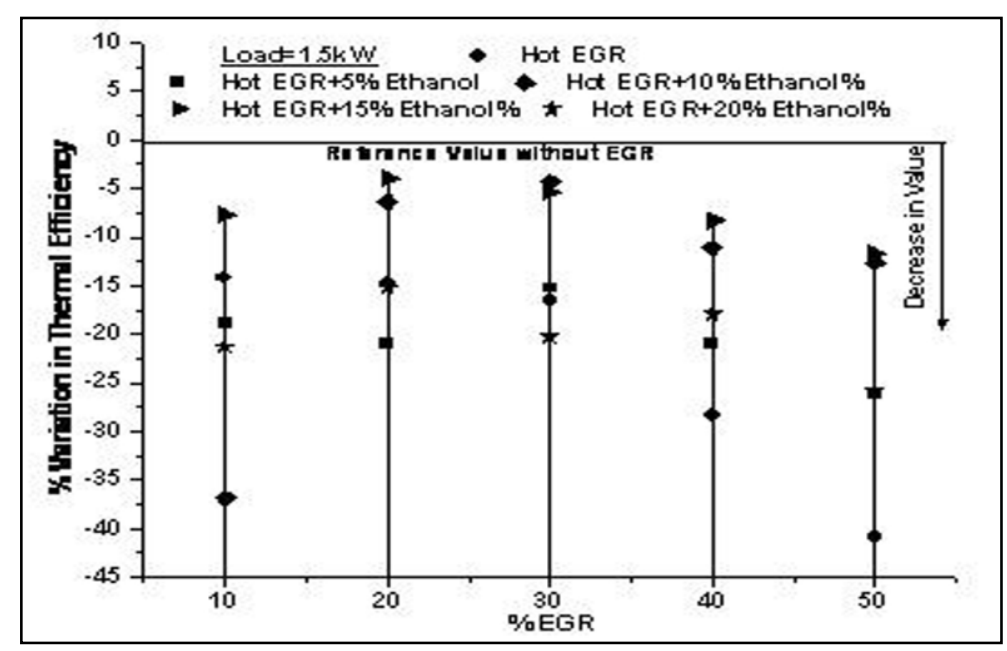

Fig. 12 Percentage variation in thermal efficiency for different ethanol fumigation percentage and EGR percentage

\section{CONCLUSION}

The objective of the experiment is to mainly investigate the effect of EGR temperature in reducing NOx emissions and associated side effects. It was found that cooling of EGR favors application of higher percentage EGR as compared to EGR without cooling. Both cooled and hot EGR applications reduce NOx but incur loss of efficiency and increase $\mathrm{HC}, \mathrm{CO} 2$ and smoke. Ethanol fumigation along with EGR is thought to compensate for the loss in efficiency and reduce other diesel emission constituents like HC and smoke as ethanol has the benefits such as higher efficiency and specific power and lower emissions. Following are the findings of the experiments.

1. Ethanol fumigation without altering the normal diesel injection rates proves to be a better option in reducing NOx accommodating higher percentage of EGR.

2. Loss in thermal efficiency associated with EGR while reducing NOx can be minimized with combining ethanol fumigation especially up to $30 \%$ EGR.

3. $10 \%$ ethanol fumigation with hot EGR is a better option for higher percentage of EGR.

4. Ethanol fumigation with EGR considerably reduces HC and smoke emissions as compared to diesel combustion with EGR.

5. Ethanol fumigation was carried in 5 to $20 \%$ of diesel injection in steps of $5 \%$. It was observed that up to $10 \%$ fumigation is found optimum considering NOx reductions and associated thermal efficiency, emission of $\mathrm{HC}$ and smoke. 


\section{References}

[1] Technical Bulletin on "Nitrogen Oxides, why and How they are controlled", EPA-456/F-99-006R, November 1999

[2] Curr Intell Bull, National Institute for Occupational Safety and Health. Carcinogenic "effects exposure to Diesel exhaust". Department of Health and Human Services Publication, 1988; 50:88-116.

[3] Lyon, France, International Agency for Research on Cancer. "Monographs on the evaluation of carcinogenic risk to humans; Diesel and gasoline engineexhaustsand some Nitroarenes". 1989; 46:458.

[4] Ladommatos N, Abdelhalim SM, Zhao H, Hu Z. "The effects of carbon dioxide in exhaust gas recirculation on Diesel engine emission”. Proc Instn Mech Engng part D J Autom Engng 1998;212:25-42.

[5] Beatric C et al. "Influence of high EGR rate on emissions of a DI Diesel engine". ASME ICE Div 1998;ICE 22: 193-201.

[6] Ladommatos, N., Abdelhalim, S. M., Zhao, H., and Hu, Z., "The Dilution, Chemical, and Thermal Effects of Exhaust as Recirculation on Diesel Engine Emissions, Part 4: Effects of Carbon Dioxide and Water Vapour", SAE Paper No. 971660 (1997).

[7] G.H. Abd-alla, "Using exhaust gas recirculation in internal combustion engines: a review" Energy Conversion and Management 43 (2002) 1027-1042

[8] Ropke, S., Schweimer, G. W., and Strauss, T. S., "NOx Formation in Diesel Engines for Various Fuels and Intake Gases", SAE Paper No. 950213 (1995).

[9] M. Dürnholz, G. Eifler, and H. Endres, "Exhaust-Gas Recirculation - A Measure to Reduce Exhaust Emissions of DI Diesel Engines", SAE Paper No. 920725 (1992).

[10] Ming Zheng Graham T. Reader, J. Gary Hawley, "Diesel Engine Exhaust Gas Recirculation-a review on advanced and novel concepts" Energy Conversion and Management 45(2004) 883-900

[11] Timothy Jacobs, Dennis Assanis, Zoran Filipi (University of Michigan); "The impact of exhaust gas recirculation on performance and emissions of a heavy-duty diesel engine", SAE paper 2003-01-1068. 2003

[12] Nidal H. Abu-Hamdeh, "Effect of cooling the recirculated exhaust gases on diesel engine emissions", Energy Conversion and Management44 (2003) 3113-3124

[13] H Van Gerpen and D B Van Meter, Department of Mechanical Engineering-Iowa State University -Ames-US, 'Emission Control in Diesel Engines by Alcohol Fumigation-A study for the U S Department of Transportation'.

[14] Heisey JB, Lestz SS. "Aqueous alcohol fumigation of a single-cylinder DI diesel engine", SAE Paper No. 811208,1981.

[15] Doann H-A. Alcohol fuels. Boulder, CO: Westview Press, 1982.

[16] Eugene EE, Bechtold RL, Timbario TJ, McCallum PW. "State-of-the-art report on the use of alcohols in diesel engines", SAE Paper No. 840118, 1984

[17] Broukhiyan EMH, Lestz SS. "Ethanol fumigation of a light duty automotive diesel engine", SAE Paper No. 811209, 1981.

[18] Baranescu RA. "Fumigation of alcohols in multi-cylinder diesel engine-evaluation of potential", SAE Paper No. 860308, 1986.

[19] Kowalewicz A., Pawlak G., Pajaczek Z., "Preliminary investigation of diesel engine with additional injection of ethyl alcohol", Journal of KONES, vol 9 no 3-4, 2002

[20] M. Abu-Qudais, O. Haddad, M. Qudaisat, “The effect of alcohol fumigation on diesel engine performance and emissions", Energy Conversion \& Management 41 (2000) 389 2399

[21] Starke K. W., Oppenlacuder K, "Ethanol an alternative fuel for diesel engine, 4th International Symposium on Alcohol Fuels Technology". Guaruja, Sp. Brasil, 1980. Paper B-59, p.635-639.

[22] M. N. Nabi, et al., "Ultra Low Emission and High Performance Diesel Combustion with Highly Oxygenated Fuel”, SAE Paper 2000$01-0231,2000$.

[23] N. Miyamoto, et al., "Smokeless, Low NOx, High Thermal Efficiency, and Low Noise Diesel Combustion with Oxygenated Agents as Main Fuel”, SAE Paper 980506, 1998.

[24] R. Baranescu, et al., "Prototype Development of a Methanol Engine for Heavy-Duty Application-Performance and Emissions", SAE Paper 891653, 1989.

[25] N. D. Brinkman, "Effect of Compression Ratio on Exhaust Emissions and Performance of a Methanol- Fueled Single-Cylinder Engine", SAE Paper 770791, 1977.

[26] P.Mohanan, M. K. Gajendra Babu, "A Simulation Model for a Methanol-Fueled Turbocharged MultiCylinder Automotive Spark Ignition Engine”, SAE Paper 912417, 1991.

[27] T. Ryan, S. Lestz, "The Laminar Burning Velocity of Isooctane, N-Heptane, Methanol, Methane and Propane at Elevated Temperatures and Pressures in the Presence of a Diluent", SAE Paper 800103, 1980.

[28] Abd Alla G.H,. "Effect of exhaust gas recirculation on the performance of a dual fual engine". PhD Thesis, Mechanical Engineering Department, Shoubra Faculty of Engineering, Zagazig University, Cairo, Egypt, 1994.

[29] Lapuerta M, Hernandez JJ, Gimenez F. "Evaluation of exhaust gas recirculation as a technique for reducing Diesel engine NO ${ }_{X}$ emissions". Proc Instn Mech Engrs Part D, J Autom Engng 2000;214:85-93.

[30] Yoshio Sato, Akira Noda, Takashi Sakamoto, "Combustion control of direct injection methanol engine using a combination of charge heating and exhaust gas recirculation"- Elsevier-Journal of Society of Automotive Engineers / JSAE Review 16 (1995) 369-373

[31] Ladommatos, N., Abdelhalim, S. M., Zhao, H., and Hu, Z., "The Dilution, Chemical, and Thermal Effects of Exhaust Gas Recirculation on Diesel Engine Emissions, Part 3: Effects of Water Vapour", SAE Paper No. 971659 (1997).

[32] Ladommatos, N., Abdelhalim, S. M., and Zhao, H., "The Effects of Carbon Dioxide in EGR on Diesel Engine Emissions", IMechE Paper No. C517/028/96 (1996). 